Revista Brasileira de Odontologia Legal - RBOL

\title{
Odontologia Legal
}

\section{EFEITO DAS ALTAS TEMPERATURAS AOS TECIDOS BUCODENTAIS E MATERIAIS ODONTOLÓGICOS: REVISÃO DE LITERATURA}

\section{Effect of high temperatures to the oro-dental tissues and dental materials: a review.}

Antonio Dionízio de ALBUQUERQUE NETO'; Aloísio de Melo FARIAS NETO; Jullyane Raíssa Duarte CAVALCANTE ${ }^{2,3}$; Darlan Kelton Ferreira CAVALCANTE $^{4}$; Thaisa Reis de Carvalho SAMPAIO ${ }^{5}$; Vanio Santos COSTA ${ }^{6}$

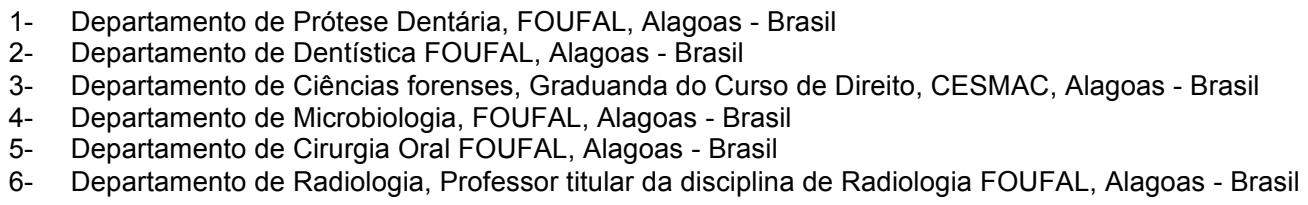

Informação sobre o artigo

Recebido: 23 Maio 2015

Aceito em: 01 Set 2015

\author{
Autor para correspondência \\ Antonio Dionízio de Albuquerque Neto \\ Faculdade de Odontologia da Universidade Federal de \\ Alagoas \\ Av Lourival Melo Mota, S/N - Tabuleiro dos Martins \\ Maceió, Alagoas, Brasil. CEP: 57072-900 \\ Email: antoniodalbuquerqueneto@gmail.com
}

\section{RESUMO}

A Odontologia Forense tem demonstrado ser de fundamental importância em investigações que visam identificar restos humanos envolvidos em incidentes de alta temperatura, como queimadas, acidentes e explosões. Os tecidos dentais e os materiais utilizados na Odontologia apresentam grande resistência às altas temperaturas, além de possuírem certa previsibilidade das mudanças cromáticas, morfológicas, superficiais, e estruturais. Deste modo, podem ser identificadas as alterações físicas que ocorrem a essas estruturas, como a estabilidade dimensional, fissuras, rachaduras, fraturas, textura alterada e alteração de cor. Além das novas tecnologias utilizadas no consultório odontológico, como exemplo os diferentes exames de imagem e sistema CAD/CAM. O presente estudo faz um apanhado, por meio de uma revisão de literatura assistemática, do efeito das altas temperaturas sobre os tecidos bucodentais e materiais odontológicos, e explana como reagem diante de cada faixa de temperatura e tempo de exposição. Ressalta a importância da correta documentação odontológica e a necessidade de novas pesquisas relacionadas ao tema, corroborando para maior eficiência da atuação da 
Odontologia Legal. A presença de um odontolegista revela-se como fundamental contribuição em investigações policiais, perícias e identificação de indivíduos.

\section{PALAVRAS-CHAVE}

Antropologia Forense, Temperatura Alta, Materiais Dentários, Odontologia Legal.

\section{INTRODUÇÃO}

A identificação é um dos principais campos de estudo nas Ciências Forenses, pois lida com o corpo humano e objetiva o estabelecimento da identidade humana. A identificação por meio do estudo dos dentes é um dos métodos mais confiáveis e é aplicado com certa frequência, configurando-se a Odontologia Forense como uma especialidade em si. Seu estabelecimento tem sido atribuído ao Dr. Oscar Amoedo, pai da Odontologia Forense, que identificou por meio das características bucodentais diversos corpos de vítimas do incêndio da Ópera de Paris, França, em $1897^{1}$.

A Odontologia Forense busca a identificação de estruturas dentais e ósseas, além de diferentes materiais utilizados pela Odontologia no tratamento e reabilitação dos pacientes. Estes tecidos e materiais estão sujeitos a alterações específicas advindas de temperaturas variáveis, que fornecem desta forma importantes subsídios post-mortem quanto ao incidente a que foram expostos e para identificação da vítima, quando comparados aos registros antemortem documentados pelo cirurgião-dentista responsável pelo tratamento do indivíduo.

A presença de um cirurgiãodentista especialista em Odontologia Forense revela-se como uma ajuda inestimável para contribuir com as investigações policiais, perícias e identificação de indivíduos. $O$ fracasso para coletar todas as informações dentais postmortem complica e atrasa a identificação do falecido. A identificação de restos humanos por desastres em massa é uma tarefa árdua, devido à destruição presente em muitos casos, seja por altas temperaturas ou impactos. Os dentes são considerados como os componentes mais resistentes do corpo humano, têm a maior resistência à maioria dos efeitos ambientais, como incêndios, dessecação e decomposição. Em 
grandes catástrofes proporcionam uma forma de identificação pessoal do indivíduo, que de outras formas poderia ser irreconhecível ${ }^{1,2}$.

Os dentes, seus tecidos e materiais utilizados na Odontologia são estudados com frequência, dada sua importância na Odontologia Forense, podem permanecer durante anos após a morte do indivíduo intactos e suportar condições extremas. Sofrem alterações biológicas, patológicas e são submetidos a procedimentos terapêuticos que os tornam identificáveis em cadáveres desconhecidos. Em incêndios, por exemplo, alguns indivíduos são submetidos a temperaturas elevadas por períodos prolongados e em muitos casos são reduzidos a elementos esqueléticos extremamente frágeis, ou mesmo cinzas $^{1,2}$.

Diante disso, o presente trabalho teve por objetivo realizar uma revisão assistemática da literatura a respeito das alterações sofridas pelos diferentes tecidos e materiais utilizados na Odontologia quando submetidos a altas temperaturas, correlacionando à utilização dessas propriedades nos estudos em Odontologia Forense.

\section{REVISÃO DE LITERATURA}

Alguns protocolos para a correta abordagem de casos de identificação de cadáveres são importantes e descritos. Segundo Hillet al. ${ }^{2}$ (2011), os restos devem ser examinados no local por um cirurgião-dentista forense e fotografado in situ, antes que o corpo seja manipulado e a cena alterada. Cada fotografia deve incluir número de identificação associado à vítima e uma escala deve estar presente na fotografia. $A$ exposição adequada e cuidadosa da cabeça e estruturas dentais deve ser realizada, com todas as estruturas frágeis sendo cimentadas com cianoacrilato ou uma substância similar. Quaisquer estruturas dentais que não possam ser recolocadas devem ser cuidadosamente recolhidas, numeradas, fotografadas e colocadas em um recipiente acolchoado e devidamente rotulado. Depois de ter sido estabilizada a cabeça e estruturas dentais, 0 crânio deve ser envolto em capa de plástico protetora suficiente para sua preservação durante 0 manuseio e transporte da cena ${ }^{2}$. 
Albuquerque Neto $A D$, Farias Neto AM, Cavalcante JRD et al.

Em um recente estudo geoquímico realizado por Brooks et al. $^{3}$ (2008) em um sítio arqueológico em Chan Chan, Peru, foi examinado um depósito de cinzas de conteúdo consistente com cinzas de carvão. A análise comparativa geoquímica de solos revelou através de radiocarbono que $\mathrm{O}$ depósito de cinzas, datado de 1312-1438 DC apresentava níveis elevados de cálcio e fósforo consistentes com a prática da cremação. Um fragmento de crânio calcinado foi recuperado e confirmado como humano por meio de radioimunoensaio de duplo anticorpo a proteína. A técnica de difração de raios- $X$ foi utilizada para sugerir que o osso tinha sido queimado a temperaturas de cerca de $520^{\circ} \mathrm{C}^{4}$.

Em revisão sistemática da literatura foi demonstrado que os restos carbonizados dentais podem ser analisados utilizando lupa estereoscópica, histologia, radiografia, microscopia eletrônica de varredura (MEV) e espectroscopia de raios $X$ por dispersão de energia (EDS). Estes métodos podem ser utilizados para estudar as alterações de cor; alterações da superfície e as alterações microscópicas em esmalte, dentina e do cemento ${ }^{5}$.

Em caso de identificação de cadáver relatado por Hill et al. ${ }^{2}$ (2011), onde houve a devida proteção dos restos, pode-se observar em fragmentos de raízes que 0 indivíduo havia realizado tratamentos endodônticos, além de restaurações. Por meio da comparação entre os registros antemortem e post-mortem, houve concordância entre os dados, o que conduziu a um relatório odontológico afirmando a identificação do indivíduo. Em outro relato do mesmo autor, o corpo não foi devidamente transportado e protegido, o que acarretou em maior perda de informações dentais, quando foi realizado o exame odontológico forense apenas foi possível observar a grade metálica em cromo-cobalto de prótese inferior, e desta forma a confiabilidade da identificação dental ficou comprometida, com relatório de provável identidade compatível $^{2}$. Devido as alterações que as estruturas bucodentais são passiveis durante catástrofes envolvendo altas temperaturas, diversos estudos tem sido realizados com intuito de catalogar 
as diferentes alterações de cor, forma, estrutura e destruição, relativas aos tecidos e seus materiais restauradores quando submetidos a diferentes temperaturas e tempo de exposição. Assim amplia-se o conhecimento a respeito da resistência destes em certas situações extremas, avalia-se desta forma a aplicabilidade dos resultados para a prática na investigação forense ${ }^{2}$.

$$
\text { Patidar et al. }{ }^{1} \text { (2010) }
$$

realizaram estudo quanto ao efeito das altas temperaturas e sua implicação em diversos materiais restauradores. Foram selecionados 72 dentes humanos hígidos que formaram 6 grupos de 12 dentes cada. Em seguida, foram restaurados com diferentes materiais, divididos em 5 grupos (Fosfato de zinco, amálgama, cimento de ionômero de vidro, $\mathrm{NiCr}$ e cerâmica), enquanto que um grupo permaneceu hígido como grupo controle. Também foram incluídas no estudo duas mandíbulas. As alterações observadas estão descritas na Tabela $1^{1}$.

$$
\text { Moharil et al. }{ }^{6}
$$
pesquisaram sobre esta temática da seguinte forma: foram selecionados oitenta elementos dentais humanos hígidos. Em seguida, eles foram divididos aleatoriamente em 4 grupos diferentes: Grupo I: 20 dentes não restaurados (íntegros); Grupo II: 20 dentes restaurados com Amálgama; Grupo III: 20 dentes restaurados com lonômero de Vidro; Grupo IV: 20 dentes restaurados com Óxido de Zinco e Eugenol. Cada amostra foi colocada em uma bandeja e então exposta ao calor direto em um forno com quatro diferentes temperaturas: $200^{\circ} \mathrm{C}$, $400^{\circ} \mathrm{C}, 600^{\circ} \mathrm{C}$ e $800^{\circ} \mathrm{C}$, com uma taxa de aumento de $30^{\circ} \mathrm{C} / \mathrm{min}$. Assim que cada temperatura específica era alcançada, as amostras eram removidas do forno e resfriadas à temperatura ambiente. Em seguida, as amostras foram examinadas tanto macroscopicamente quanto através do estereomicroscópio. Os resultados obtidos encontram-se resumidos na Tabela 2 .

Os dentes são objetos duros, resistentes, mas passíveis de modificação devido a padrões mastigatórios, alimentares, hábitos ocupacionais, e tabagismo. Por exemplo, entalhes característicos nas bordas incisais são observados nos dentes de costureiras que 
passam o fio de algodão por entre seus dentes antes de inserir na agulha. A coloração poderá ser alterada devido alimentação hiperpigmentada ou tabagismo ${ }^{7}$.

Igualmente os tecidos dentais sofrem alterações quando expostos a temperaturas aumentadas de forma abrupta ou constante.
Desta forma, em estudo realizado por Pol e Gosavi ${ }^{8}$ (2014), 75 dentes hígidos foram separados em 5 grupos de forma aleatória a fim de se avaliar o comportamento dos diferentes tecidos dentais submetidos à altas temperaturas.

Tabela 1 - Informações relativas ao estudo realizado por Patidar et al. ${ }^{1}$ (2010).

\begin{tabular}{|c|c|c|c|c|}
\hline & $400^{\circ} \mathrm{C} / 5 \mathrm{~min}$ & $400^{\circ} \mathrm{C} / 15 \mathrm{~min}$ & $400^{\circ} \mathrm{C} / 30 \mathrm{~min}$ & $1100^{\circ} \mathrm{C} / 15 \mathrm{~min}$ \\
\hline HÍGIDO & $\begin{array}{l}\text { Descoloração } \\
\text { acastanhada }\end{array}$ & Castanho escuro & Cinza carvão & $\begin{array}{l}\text { Cinza com múltiplas } \\
\text { fissuras e fragmentos }\end{array}$ \\
\hline $\begin{array}{l}\text { FOSFATO DE } \\
\text { ZINCO }\end{array}$ & $\begin{array}{c}\text { Contração e } \\
\text { discreto GAP } \\
\text { marginal }\end{array}$ & $\begin{array}{c}\text { Contração } \\
\text { marginal visível e } \\
\text { superfície irregular } \\
\text { e áspera }\end{array}$ & $\begin{array}{l}\text { Acentuado } \\
\text { GAP marginal }\end{array}$ & $\begin{array}{l}\text { Dentes frágeis com } \\
\text { restauração } \\
\text { desordenada, cinza } \\
\text { pálida }\end{array}$ \\
\hline AMALGAMA & $\begin{array}{l}\text { Expansão do } \\
\text { material, } \\
\text { superfície } \\
\text { áspera }\end{array}$ & $\begin{array}{c}\text { Perda do contorno } \\
\text { marginal e contato } \\
\text { oclusal }\end{array}$ & $\begin{array}{l}\text { Superfície } \\
\text { irregular e } \\
\text { grosseira, } \\
\text { várias } \\
\text { rachaduras e } \\
\text { GAP marginal. }\end{array}$ & $\begin{array}{l}\text { Esferas metálicas } \\
\text { acinzentadas, } \\
\text { descoloração, dentes } \\
\text { fraturados }\end{array}$ \\
\hline CIV & $\begin{array}{l}\text { Perda do } \\
\text { brilho, } \\
\text { descoloração } \\
\text { cinza-escuro } \\
\text { e contração } \\
\text { marginal }\end{array}$ & $\begin{array}{c}\text { Descoloração } \\
\text { cinza e superfície } \\
\text { rugosa }\end{array}$ & $\begin{array}{l}\text { Contração e } \\
\text { rachaduras }\end{array}$ & $\begin{array}{c}\text { Restauração não } \\
\text { suportada pelo dente } \\
\text { e fraturada }\end{array}$ \\
\hline $\mathrm{NiCr}$ & $\begin{array}{l}\text { Leve perda } \\
\text { de esmalte }\end{array}$ & $\begin{array}{l}\text { Deterioração } \\
\text { visível do cimento } \\
\text { que resulta em } \\
\text { perda de vedação } \\
\text { marginal }\end{array}$ & $\begin{array}{l}\text { Enegrecido e } \\
\text { brilhante, } \\
\text { coroa } \\
\text { facilmente } \\
\text { deslocada }\end{array}$ & $\begin{array}{c}\text { Superfície áspera e } \\
\text { amassada, coroa } \\
\text { desalojada }\end{array}$ \\
\hline Cerâmica & $\begin{array}{c}\text { Afrouxamento } \\
\text { da coroa sem } \\
\text { alterações de } \\
\text { cor visíveis }\end{array}$ & $\begin{array}{l}\text { Sem alterações } \\
\text { dignas de nota }\end{array}$ & $\begin{array}{c}\text { Ligeira } \\
\text { descoloração } \\
\text { e coroas } \\
\text { deslocadas }\end{array}$ & $\begin{array}{c}\text { Perda de morfologia e } \\
\text { textura da cerâmica. } \\
\text { Fadiga do núcleo e } \\
\text { deslocamento da } \\
\text { coroa }\end{array}$ \\
\hline Osso mandibular & & $\begin{array}{l}\text { Superfície preta e } \\
\text { granular. Fratura } \\
\text { transversa }\end{array}$ & & $\begin{array}{c}\text { Grande encolhimento } \\
\text { e deformação do osso } \\
\text { mandibular. Cor cinza } \\
\text { pálido e múltiplas } \\
\text { fraturas }\end{array}$ \\
\hline
\end{tabular}


Tabela 2 - Dados retirados de estudo realizado por Moharil et al. ${ }^{6}$ (2014)

\begin{tabular}{|c|c|c|c|c|}
\hline & $200^{\circ} \mathrm{C}$ & $400^{\circ} \mathrm{C}$ & $600^{\circ} \mathrm{C}$ & $800^{\circ} \mathrm{C}$ \\
\hline DENTE HÍGIDO & $\begin{array}{l}\text { Coloração } \\
\text { marrom-claro na } \\
\text { coroa e na raiz e } \\
\quad \text { fendas ou } \\
\text { fraturas na raiz. }\end{array}$ & $\begin{array}{c}\text { A coroa } \\
\text { permaneceu } \\
\text { com uma } \\
\text { coloração } \\
\text { marrom-claro e } \\
\text { micro fraturas } \\
\text { na superfície. A } \\
\text { raiz mostrou-se } \\
\text { acinzentada ou } \\
\text { enegrecida com } \\
\text { extensão das } \\
\text { fraturas }\end{array}$ & $\begin{array}{c}\text { A coroa foi } \\
\text { destruída em } \\
\text { pedaços. A } \\
\text { raiz } \\
\text { apresentou-se } \\
\text { com uma } \\
\text { coloração } \\
\text { enegrecida e } \\
\text { fraturas }\end{array}$ & $\begin{array}{l}\text { Destruição total da } \\
\text { coroa A dentina } \\
\text { exposta da raiz se } \\
\text { apresentava cinza- } \\
\text { escuro, com fendas } \\
\text { verticais na raiz } \\
\text { branco-opaca }\end{array}$ \\
\hline $\begin{array}{c}\text { RESTAURADOS } \\
\text { COM } \\
\text { AMÁLGAMA }\end{array}$ & $\begin{array}{l}\text { Leve retração da } \\
\text { restauração. } \\
\text { Bolhas na } \\
\text { superfície do } \\
\text { AMG }\end{array}$ & $\begin{array}{l}\text { Maior retração. } \\
\text { Perda do } \\
\text { selamento } \\
\text { marginal }\end{array}$ & $\begin{array}{c}\text { Coroa } \\
\text { fraturada, com } \\
\text { a forma da } \\
\text { restauração } \\
\text { preservada, } \\
\text { porém com } \\
\text { fraturas }\end{array}$ & $\begin{array}{c}\text { Perda de selamento } \\
\text { marginal e } \\
\text { rachaduras no } \\
\text { material }\end{array}$ \\
\hline $\begin{array}{c}\text { RESTAURAÇÕES } \\
\text { COM CIMENTO } \\
\text { DE IONÔMERO } \\
\text { DE VIDRO }\end{array}$ & $\begin{array}{c}\text { A restauração } \\
\text { extruiu da } \\
\text { cavidade, com } \\
\text { perda de vedação } \\
\text { marginal }\end{array}$ & $\begin{array}{c}\text { As restaurações } \\
\text { mostraram uma } \\
\text { mudança na cor } \\
\text { para castanho- } \\
\text { claro }\end{array}$ & $\begin{array}{l}\text { A perda da } \\
\text { porção } \\
\text { superficial da } \\
\text { estrutura da } \\
\text { coroa } \\
\text { juntamente } \\
\text { com uma } \\
\text { parte da } \\
\text { restauração }\end{array}$ & $\begin{array}{l}\text { Apenas uma parte } \\
\text { da estrutura } \\
\text { coronária, } \\
\text { juntamente com a } \\
\text { restauração } \\
\text { permaneceu }\end{array}$ \\
\hline $\begin{array}{c}\text { RESTAURADOS } \\
\text { COM ÓXIDO DE } \\
\text { ZINCO E } \\
\text { EUGENOL }\end{array}$ & $\begin{array}{l}\text { Restauração } \\
\text { mostrou áreas } \\
\text { marrom-claro e } \\
\text { extruiu da } \\
\text { cavidade }\end{array}$ & $\begin{array}{l}\text { Restauração } \\
\text { cinza escura, } \\
\text { extruída, } \\
\text { porções } \\
\text { quebradas e } \\
\text { fissuras na } \\
\text { superfície } \\
\text { remanescente, } \\
\text { além de perda } \\
\text { de vedação } \\
\text { marginal }\end{array}$ & $\begin{array}{c}\text { Contorno da } \\
\text { cavidade era } \\
\text { perceptível, } \\
\text { em secção } \\
\text { transversal da } \\
\text { restauração } \\
\text { não houve } \\
\text { mudança na } \\
\text { cor }\end{array}$ & $\begin{array}{c}\text { A restauração foi } \\
\text { perdida visto que a } \\
\text { coroa foi quebrada } \\
\text { por } \\
\text { completo }\end{array}$ \\
\hline
\end{tabular}

As amostras de cada grupo foram expostas em um forno com cinco temperaturas préestabelecidas, em tempos diferentes, $\left(200^{\circ} \mathrm{C}, 400^{\circ} \mathrm{C}, 600^{\circ} \mathrm{C}\right.$, $800^{\circ} \mathrm{C}$ e $1000^{\circ} \mathrm{C}$ ), uma temperatura para cada grupo. Uma vez que a temperatura desejada foi atingida, as amostras de dentes foram mantidas no interior do forno durante 15 minutos, após os quais elas foram removidas e deixadas arrefecer à temperatura ambiente. Em seguida, a amostra de dente foi examinada por microscópio eletrônico de varredura sob magnificação $\times 1000$. Os resultados estão condensados na Tabela 3. 
Tabela 3 - Estudo realizado por Pol e Gosavi $^{8}$ (2014) referente às alterações em tecidos dentais sob altas temperaturas.

\begin{tabular}{|c|c|c|c|c|c|}
\hline $\begin{array}{l}\text { Dentes } \\
\text { hígidos }\end{array}$ & $200^{\circ} \mathrm{C}$ & $400^{\circ} \mathrm{C}$ & $600^{\circ} \mathrm{C}$ & $800^{\circ} \mathrm{C}$ & $1000^{\circ} \mathrm{C}$ \\
\hline ESMALTE & $\begin{array}{c}\text { Pequenas } \\
\text { rachaduras } \\
\text { padronizadas }\end{array}$ & $\begin{array}{l}\text { Rachaduras } \\
\text { numerosas e } \\
\text { pronunciadas na } \\
\text { área de junção } \\
\text { amelocementária } \\
\text { (JAC) }\end{array}$ & $\begin{array}{l}\text { Rachaduras } \\
\text { mais evidentes } \\
\text { em toda a } \\
\text { extensão do } \\
\text { esmalte }\end{array}$ & $\begin{array}{l}\text { Surgiment } \\
\text { o de } \\
\text { algumas } \\
\text { zonas } \\
\text { fundidas }\end{array}$ & $\begin{array}{l}\text { Fragmentos } \\
\text { diminutos } \\
\text { estrutura } \\
\text { prismática do } \\
\text { esmalte ainda } \\
\text { pudesse ser } \\
\text { reconhecida }\end{array}$ \\
\hline DENTINA & $\begin{array}{l}\text { Sem } \\
\text { alterações }\end{array}$ & $\begin{array}{c}\text { Leves rachaduras } \\
\text { padronizadas }\end{array}$ & $\begin{array}{l}\text { Diâmetro dos } \\
\text { túbulos } \\
\text { dentinários } \\
\text { reduzidos }\end{array}$ & $\begin{array}{l}\text { Notou-se } \\
\text { debris } \\
\text { cobrindo } \\
\text { os túbulos } \\
\text { dentinários }\end{array}$ & $\begin{array}{l}\text { Dentina } \\
\text { encolhida } \\
\text { recoberta por } \\
\text { grânulos, com } \\
\text { aparência } \\
\text { fundida }\end{array}$ \\
\hline CEMENTO & $\begin{array}{c}\text { Pequenas } \\
\text { rachaduras } \\
\text { padronizadas }\end{array}$ & $\begin{array}{c}\text { Rachaduras mais } \\
\text { numerosas e } \\
\text { pronunciadas na } \\
\text { área de JAC }\end{array}$ & $\begin{array}{l}\text { Rachaduras } \\
\text { evidentes com } \\
\text { exposiçãoda } \\
\text { dentina } \\
\text { subjacente }\end{array}$ & $\begin{array}{l}\text { Aparência } \\
\text { de favo de } \\
\text { mel na } \\
\text { JAC }\end{array}$ & $\begin{array}{l}\text { O cemento } \\
\text { não } \\
\text { identificável, } \\
\text { pois } \\
\text { apresentava } \\
\text { grânulos }\end{array}$ \\
\hline
\end{tabular}

Pueyo $^{9}$ (1994) relatou que tratamentos endodônticos possuem valor extraordinário para a identificação, pois com as radiografias anteriores do cirurgiãodentista que realizou o tratamento endodôntico, se torna fácil a comparação com a radiografia a ser obtida após o desastre. No entanto, Botha $^{10}$ (1986) relatou que dentes com suas raízes obturadas com cones de guta-percha foram colocados para experiência em um incinerador à $815^{\circ} \mathrm{C}$ por 90 minutos. $O$ material obturador ferveu para fora do forame apical de dentes com canais amplos, porém não foi notado este extravasamento nos canais de raízes mais atrésicas. A comparação das radiografias de pré e pós-incineração revelou zonas radiolúcidas nos preenchimentos dos canais dos dentes submetidos ao calor. Achados similares foram encontrados quando se utilizaram endometazona e eugenol como selador ou material de preenchimento da raiz ${ }^{9,10}$.

Dentes de porcelana têm fusão entre $870^{\circ} \mathrm{C}$ e $1370^{\circ} \mathrm{C}$. Trabalhos experimentais têm demonstrado que os dentes de porcelana não sofrem qualquer dano quando colocados em fornalha 
crematória à $900^{\circ} \mathrm{C}$ por 90 minutos. Segundo Pueyo ${ }^{9}$ (1994), as porcelanas se classificam em três grupos: alta, média e baixa temperatura, com temperaturas de fusão de $1300^{\circ}$ a $1370^{\circ} \mathrm{C}$ para o primeiro; de $1090^{\circ} \mathrm{C}$ a $1260^{\circ} \mathrm{C}$ para o segundo; e de $870^{\circ} \mathrm{C}$ a $1065^{\circ} \mathrm{C}$ para o terceiro grupo. Um pino de aço cimentado no canal radicular não mostrou nenhuma mudança quando aquecido à $815^{\circ} \mathrm{C}$ por 90 minutos em estudo do mesmo autor. Enquanto que bases de prótese total, prótese parcial e dentes em acrílico polimetilmetacrilato despolimerizam o monômero a $450^{\circ} \mathrm{C}$.

Em estudo realizado por Pol e Gosavi ${ }^{8}$ (2014) diferentes restaurações em elementos dentais foram expostas à temperatura fixa de $1000^{\circ} \mathrm{C}$. A resina composta foi desalojada da cavidade com alguns restos carbonizados e coloração rósea. Coroas cerâmicas apresentaram inúmeras bolhas em sua superfície, enquanto restaurações com cimento de ionômero de vidro (CIV) foram extruídas da cavidade e apresentaram coloração enegrecida. Após a exposição ao calor foi possível visualizar através do microscópio eletrônico de varredura as marcas deixadas pelos instrumentos cortantes utilizados no preparo da cavidade $\mathrm{e}^{8,9}$.

A tecnologia CAD/CAM e ortopantomografia, foram utilizadas para conversão dos caracteres morfológicos das faces dentais em um conjunto de códigos, utilizandose a técnica descrita por Lee et al. ${ }^{11}$ (2004), onde os dados obtidos eram convertidos em 4 códigos (QR), um para cada hemiarco. Os códigos QR são barras bidimensionais que podem armazenar dados e facilitar a transmissão e comparação de dados nas ciências forenses ${ }^{7}$.

Os frequentes traumas na região maxilofacial implicam em tratamento que muitas vezes exige o uso de placas de titânio para realização da fixação interna rígida. Estas placas são biocompatíveis e permanecem com o indivíduo para o resto da vida, tornando-se assim uma informação crucial para a Odontologia Forense. O titânio possui características interessantes, tais como: baixa condutibilidade elétrica e térmica, ponto de fusão alto $\left(1650^{\circ} \mathrm{C}\right)$ e maior resistência que o aço com $45 \%$ menos de peso. De outro modo, o titânio também tem sido utilizado em marcadores 
codificados inclusos na fabricação de próteses. Desta forma, o indivíduo terá uma identidade universal que em caso de desastre não irá demandar outras formas mais complexas de identificação, tornando-a prática e confiável ${ }^{12}$.

Os dentes são uma fonte privilegiada de DNA nuclear por várias razões. Devido a sua composição singular e localização nas maxilas e mandíbula, são em grande parte protegidos das condições ambientais e físicas que atuam de modo a acelerar os processos de decomposição postmortem e decaimento de DNA. Por conseguinte, o DNA extraído a partir de dentes é muitas vezes de qualidade superior e é menos propenso à contaminação que o DNA extraído de ossos ${ }^{13}$.

\section{DISCUSSÃO}

Diante dos dados supracitados, nota-se a importância da Odontologia forense na identificação de indivíduos. Como exemplo podem ser citadas as impressões digitais que são individualizadas em milhões de diferentes combinações, em semelhança com a cavidade bucal, que apresenta 160 faces dentais, alterações de ordem patológica ou traumática, morfologia radicular, restaurações e próteses, número de dentes, defeitos ósseos, tratamento ortodôntico ou endodôntico, rugosidades palatinas, freios linguais e labiais. Esse contexto reforça a necessidade de uma documentação completa e cuidadosa por parte do cirurgiãodentista, pois além da necessidade clínica e legal, essa documentação pode servir como base para a elucidação de um caso pericial, este podendo eventualmente ser solicitada para contribuir com uma identificação cadavérica ${ }^{14,15}$.

Os estudos de Patidar et al. ${ }^{1}$ (2010) e Moharil et al. ${ }^{6}$ (2014) foram realizados in vitro. Outrossim, resultados exatos não podem ser obtidos quando o corpo é sujeito a uma fonte de calor intensiva in vivo. No entanto, são úteis quanto às valiosas informações referentes à previsibilidade dos efeitos, que dependem de diversas variáveis, tais como a intensidade do calor, a proteção do tecido, duração da exposição, a presença de acelerador e a forma utilizada para extinguir o fogo. Como exemplo disto, Chavéz ${ }^{16}$ (1966) concluiu que 
durante episódios de incêndios a boca pode se fechar e formar uma espécie de "caixa forte" que protege os tecidos do interior da boca da ação do fogo, colaborando ao constante estado de umidade em que se encontra a boca. $\mathrm{O}$ palato pode conservar a sua morfologia macroscópica sem sofrer alterações pela ação do fogo, sendo isso de grande importância se levado em consideração que aí se encontram valiosos elementos identificadores (papilas palatinas). A língua normalmente se intumesce $e$ protege $o$ palato e durante 0 incêndio, o gás produzido no trato gastrointestinal e pulmões, leva a uma protrusão da língua que tende a proteger os dentes. Além disso, os ossos e músculos que compõem a estrutura maxilofacial protegem a cavidade oral das altas temperaturas. Sendo assim, os tecidos dentais apresentam resistência a temperaturas mais altas in vivo, quando comparados com os estudos citados ${ }^{1,6,16}$.

A maioria dos estudos microscópicos de esmalte apresentou alterações estruturais em $800^{\circ} \mathrm{C}$, enquanto que a dentina mostrou alterações a uma temperatura comparativamente mais baixa, de $600^{\circ} \mathrm{C}$. Os achados normalmente encontrados em dentes incinerados são relativos a alterações de cor, matiz da restauração e sua aparência externa. As alterações de cor dos tecidos dentais são as mais observadas diante das exposições a altas temperaturas. $O$ fato da sensibilidade à mudança de cor é provavelmente devido ao calor que leva à desnaturação das ligações dentro das moléculas de colágeno helicoidal. Isto afeta o arranjo do colágeno que está relacionado a absorção da luz visível. Os dentes são surpreendentemente resistentes ao calor, quando submetido a ele de forma gradual, mas, se aquecido severamente $\mathrm{O}$ dente pode se desintegrar; observando-se vestígios/remanescentes dentais, mesmo que com severas alterações, a temperaturas de até $1200^{\circ} \mathrm{C}^{1,4,6,8}$.

As coroas dentais comumente tendem a destruição durante exposição a temperaturas extremas, devido a razões como o aumento da pressão interna da câmara pulpar, contração na matriz do esmalte e dentina, assim como a desidratação. A ausência dos fatores protetores aos dentes 
Albuquerque Neto $A D$, Farias Neto AM, Cavalcante JRD et al.

existentes no indivíduo vivo do indivíduo podem identificá-lo. Em submetido às altas temperaturas pode ter predisposto a uma evaporação precoce de componentes orgânicos com ruptura ou explosão da coroa a cerca de $800^{\circ} \mathrm{C}$ nos estudos in vitro. Coroas restauradas podem resistir a temperaturas mais altas que as hígidas, pois a cavidade preparada pode servir para libertar a pressão, através do deslocamento/extrusão da restauração. Já as raízes dos dentes contêm menos umidade, não são incorporados em esmalte $\mathrm{e}$ estão protegidas no interior do osso alveolar, tornando-se menos propensas a sofrer alterações ${ }^{2}$. No entanto, os dentes restaurados com os diversos materiais apresentaram fendas e fissuras a temperaturas mais baixas do que os dentes hígidos. Isto pode ser justificado devido à alteração na integridade estrutural do dente durante a preparação da cavidade, além das diferenças de coeficiente de expansão linear entre os materiais e tecidos $^{1,4,6,9}$.

O uso de radiografia pode ser bastante útil, visto que fornece informações da estrutura óssea, periodontal, dental e assim quando comparada a radiografias anteriores elementos dentais pode-se proceder ao preenchimento do alvéolo com alginato e sulfato de bário, obtendose assim uma cópia fiel da raiz perdida. As raízes carregam diversas características que podem ser visualizadas diante de uma radiografia: dilaceração radicular, tratamento endodôntico, posição e número de raízes ${ }^{1,7}$.

Os achados relatados em diferentes estudos referentes a desenvoltura da amálgama diante de temperaturas extremas, discorrem a respeito da contração da restauração e perda de vedação marginal, que justifica-se pela perda de matéria orgânica e umidade da dentina, além da formação de bolhas na superfície do amálgama, que ocorre devido à evaporação de mercúrio. Com a perda do mercúrio, a liga usualmente começa a se pulverizar em complexos prataestanho e cobre-zinco. A diferença na composição de amálgama e uma inconsistência nos percentuais de mercúrio, prata e cobre encontrados em amálgamas disponíveis em diferentes partes do mundo podem ser responsáveis por discrepâncias de resistência e ponto de fusão. 
Alguns autores relatam que restaurações de amálgama podem resistir a temperaturas tão elevadas, como $870^{\circ} \mathrm{C}^{1,6,17}$.

Como descrito por Pueyo $^{9}$ (1994), dentre os materiais utilizados para restauração da função dental, as cerâmicas apresentam alta resistência a exposição em altas temperaturas. Isso foi confirmado pelo estudo realizado por Pol e Gosavi ${ }^{8}$ (2014), ficando clara a superioridade das cerâmicas quando comparadas a resinas compostas e cimento de ionômero de vidro em exposição a $1000^{\circ} \mathrm{C}$ durante 15 minutos quando a temperatura for atingida ${ }^{8,9}$.

Em estudo, realizado por Patidar et al. $^{1}$ (2010), relativo a exposição de mandíbulas humanas a altas temperaturas, observaramse alterações como fraturas, encolhimento, deformação e modificações da coloração. Herrmann e Bennett ${ }^{18}$ (1999) sugeriram que fraturas traumáticas prévias eram difíceis de distinguir de fraturas relacionadas estritamente com o calor. Esse é um dado importante quando da necessidade de identificação de vítimas de acidentes, agressões físicas ou violências prévias à exposição a temperaturas de pico. Em estudo de Christensen $^{19}$ (2002) foi constatada a maior predisposição à destruição e fragmentação devido altas temperaturas do osso osteoporótico quando comparado ao osso normal ${ }^{1,4,18,19}$.

Outra forma de identificação utiliza o padrão socioeconômico da vítima para relacionar os materiais utilizados em tratamentos odontológicos pregressos em seus dentes e maxilares para desta forma identificar o cadáver. Por exemplo, implantes de titânio e próteses fixas em cerâmica, denotam que o paciente possuía uma condição econômica boa. O uso de materiais odontológicos antigos, já em desuso, como o ouro, confere ao indivíduo uma idade mais avançada. Geralmente, é possível relacionar o material e técnica utilizados à época ou país que se realizou 0 tratamento ${ }^{5,7}$.

A Odontologia tem se beneficiado do avanço de diversos materiais estéticos, no entanto, o uso de materiais tradicionais não foi eliminado. Desta forma, observa-se a vastidão de materiais dentais utilizados pelos cirurgiões-dentistas, criando uma gama enorme de possibilidades quanto a 
identificação pessoal de cadáveres, baseado na documentação odontológica e alterações típicas de cada material.

\section{CONSIDERAÇÕES FINAIS}

As características orais e os diversos tratamentos dentais realizados no paciente durante sua vida resultam em um conjunto de particularidades que devem ser bem relatadas nos prontuários.
Essas informações são úteis para identificar cadáveres que sofreram alterações por exposição a altas temperaturas. Os dentes e os materiais odontológicos sofrem diversas modificações quando aquecidos e cada material ou tecido possui características próprias. A particularidade de cada material torna possível estipular o tempo e a que temperatura que foi exposto o cadáver.

\begin{abstract}
Forensic Dentistry plays an important role in forensic investigations aiming identification of human remains that involve high temperature incidents, such as fires and explosions. Dental tissues and materials have great resistance to high temperatures, and their chromatic, morphologic, superficial, and structural changes are quite predictable. Thus, it is possible to identify physical changes occurring to those structures, such as dimensional instability, fissures, cracks, fractures, texture change, and color variation. In addition, there are new technologies used in dental practices, for example, different imaging techniques and CAD / CAM system that can help forensic investigations. This study provides a non-systematic review of literature of how high temperatures affects oro-dental tissues and dental materials, it also aims to explain how they react to different temperature ranges and exposure times. This study emphasizes the importance of keeping proper dental records and the necessity of further related research, which are essential for the success of Forensic Dentistry operations. Forensic dentists are of great importance and can contribute to police investigations, surveys, and identification of human remains by dental evidence.
\end{abstract}

\title{
KEYWORDS
}

Forensic Anthropology, hot temperature, dental materials, Forensic Dentistry.

\section{REFERÊNCIAS}

1. Patidar KA, Parwani $R$, Wanjari $S$. Effects of high temperature on different restorations in forensic identification: Dental samples and mandible. J Forensic Dent Sci. 2010; 2(1):37-43. doi:10.4103/0974-2948.71056. 
2. Hill AJ, Lain R, Hewson I. Preservation of dental evidence following exposure to high temperatures. Forensic Sci Int. 2011; 205(1-3):40-3. doi:10.1016/j.forsciint.2010.08.011.

3. Brooks WE, Galvez Mora C, Jackson JC, McGEEHIN JP, Hood DG. Coal and Cremation At the Tschudi Burn, Chan Chan, Northern Peru. Archaeometry. 2008; 50(3):495-515. doi:10.1111/j.1475-

4754.2007.00358.x.

4. Ubelaker DH. The forensic evaluation of burned skeletal remains: A synthesis. Forensic Sci Int. 2009; 183(1-3):1-5.

doi:10.1016/j.forsciint.2008.09.019.

5. Delattre VF. Burned beyond recognition: Systematic approach to the dental identification of charred human remains. J Forensic Sci. 2000; 45(3):589-596.

6. Moharil R, Dive A, Thakur S, Bodhade A, Dhobley A, Bagdey S. Effect of various temperatures on restored and unrestored teeth: A forensic study. J Forensic Dent Sci. 2014; 6(1):62. doi:10.4103/0975-1475.127777.

7. Reesu GV, Augustine J, Urs AB. Forensic considerations when dealing with incinerated human dental remains. J Forensic Leg Med. 2015; 29:13-17.

doi:10.1016/j.jflm.2014.10.006.

8. Pol C, Gosavi S. Scanning electron microscopic analysis of incinerated teeth: An aid to forensic identification.

J Oral Maxillofac Pathol. 2014;
18(1):32.

doi:10.4103/0973-

029X.131889.

9. Pueyo M. Odontologya Legal $Y$ Forense. 1st ed. (Masson, ed.). Barcelona; 1994.

10. Botha $\mathrm{C}$. The dental identification of fire victims. J Forensic Odontostomatol. 1986; 4(2):67-75.

11. Lee SS, Choi JH, Yoon CL, Kim CY, Shin KJ. The diversity of dental patterns in the orthopantomography and its significance in human identification. J Forensic Sci. 2004; 49(4):784-786.

doi:10.1520/JFS2003339.

12. Srinivasan S. Evaluation of the efficacy of titanium plates as denture markers under various heat sources and pressure - An in vitro study ' E. 2015; $7(1): 5-8$.

doi:10.4103/09751475.150320.

13. Higgins D, Austin JJ. Teeth as a source of DNA for forensic identification of human remains: $A$ Review. Sci Justice. 2013; 53(4):433441. doi:10.1016/j.scijus.2013.06.001.

14. Saferstein R. Criminalistic: An Introduction to Forensic Science. 2nd ed. (Prentice-Hall, ed.). New Jersey; 1981.

15. Poller B. Forensic odontology: a responsibility of the general practitioner. Acad Gen Dent. 1975; 23(5):33-36.

16. Cháves B. Valor probatório de los tejidos bucodentários para El reconocimiento de las piezas 
Albuquerque Neto AD, Farias Neto AM, Cavalcante JRD et al.

dentárias. Rev Polic Tec. 1966;

341/342:90-95.

17. Selvarason T. Significance of restorations in forensic identification. $\mathrm{J}$ Forensic Dent Sci. 2014; 6(3):20142016.

18. Herrmann NP, Bennett JL. The differentiation of traumatic and heatrelated fractures in burned bone. J Forensic Sci. 1999; 44(3):461-469.

19. Christensen AM. Experiments in the combustibility of the human body. J Forensic Sci. 2002; 47(3):466-470 